\title{
Carcinoma of the vagina presenting as a ruptured procidentia with an entero-vaginal fistula and prolapse of the small bowel
}

\author{
J. M. T. HowAT \\ M.D., F.R.C.S. \\ I. MOHANDAS \\ M.R.C.O.G.
}

\author{
L. STASSAN \\ F.R.C.S. \\ E. DAW \\ F.R.C.O.G.
}

Departments of Surgery and Gynaecology, North Manchester General Hospital, Crumpsall, Manchester

\section{Summary}

A case of a carcinoma of the vagina which presented as a ruptured procidentia with an entero-vaginal fistula and prolapse of the small bowel is reported.

KEY WORDS: faecal incontinence.

\section{Introduction}

Chronic genital prolapse may be associated with carcinoma of the cervix and more rarely with carcinoma of the vagina (Daw, 1972a). The present case is of a carcinoma of the vagina which presented in an unusual way.

\section{Case report}

The 74-year-old widow was admitted as an emergency with a 4-day history of faecal incontinence and loose stools. Whilst on the lavatory she had felt something 'give way' and this prompted her referral to Casualty. She had had one normal pregnancy and delivery 50 years previously. The menopause had occurred 24 years previously and she denied any postmenopausal bleeding or discharge. She admitted that she had had a uterine prolapse for 1 year but had not noticed any change in this.

On examination she had a complete procidentia and $15-20 \mathrm{~cm}$ of ruptured and everted small bowel hanging from the perineum. She was transferred to the operating theatre once blood had been cross matched and her blood count and electrolytes shown to be normal. Further examination was carried out under anaesthetic. There was a $10 \mathrm{~cm}$ diameter malignant-looking ulcer on the posterior wall of the procidentia stretching from the cervix to the fourchette. Small bowel, which had been adherent to the tumour in the pouch of Douglas, had perforated resulting in an enterovaginal fistula. The bowel had prolapsed through the ulcer at two separate points and had become everted (Fig. 1). A combined abdomino-vaginal approach was employed to reduce the prolapsed bowel and uterus. Fifteen centimetres of small bowel were resected and continuity restored with an end-to-end anastomosis. A total hysterectomy and bilateral salpingooophorectomy was also performed but removal of the vaginal tumour was impossible so several biopsies were taken. Closure of the vault also closed the ulcer in the vaginal tumour.

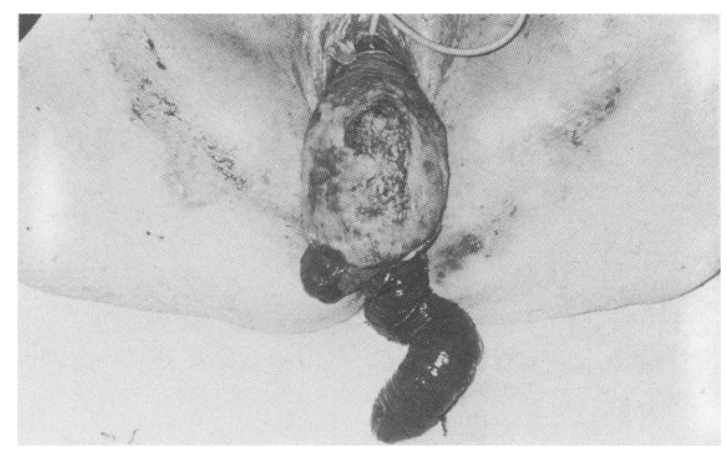

FIG. 1. Complete procidentia; vaginal carcinoma and prolapsed everted small bowel.

Post-operatively the patient did extremely well and was discharged home on the twentieth post-operative day. The patient was referred for further treatment of her residual vaginal carcinoma by radiotherapy.

Histological examination showed the vaginal ulcer to be squamous carcinoma. Invasion of the everted ulcerated small bowel by tumour was also shown though there was no malignancy elsewhere in the uterus or appendages.

\section{Discussion}

Vaginal carcinoma represents only $1-2 \%$ of all gynaecological cancer. It is usually squamous in 
more than $95 \%$ of cases though occasionally adenocarcinoma, and occurs mostly in the upper third of the vagina with no predilection for anterior or posterior wall. It occurs at an average age of 55-60 years; presents as post-menopausal bleeding or an offensive vaginal discharge of 2-3 months duration in a married multiparous patient (Daw, 1971). Vaginal vault laceration without previous vaginal surgery and not during coitus is rare (Daw, 1972b).

Enterovaginal fistulae are usually associated with intestinal disease, especially diverticulitis, malignant tumours, tuberculosis and obstruction. More rarely carcinoma of the vagina or cervix or following radiotherapy for these conditions may produce these fistulae (Jeffcoate, 1972).

Infarction of the sigmoid colon in an (unruptured) uterovaginal prolapse has been reported (Thomson and Munro, 1983) but we cannot find a report of a patient presenting as did this one.

\section{References}

DAw, E. (1971) Primary carcinoma of the vagina. Journal of Obstetrics and Gynaecology of the British Commonwealth, 78, 853. DAw, E. (1972a) Carcinoma of cervix in association with procidentia. British Journal of Clinical Practice, 26, 197.

DAw, E. (1972b) Coital vaginal vault laceration. Obstetrics and Gynecology, 40, 451.

JefFCOATE, T.N. (1972) Principles of Gynaecology, 3rd ed., p. 310. Butterworths, London.

ThOMAS, H.J. \& MUNRO, A. (1983) Infarction of the sigmoid Colon in a uterovaginal prolapse. British Journal of Surgery, 70, 35.

(Accepted 23 May 1983) 